\title{
Multi responses optimization of decarboxylation process of Free Fatty Acid (FFA) into biodiesel using Grey Relational Analysis (GRA)
}

\author{
Erfina Oktariani ${ }^{1, *}$, and Rita Istikowati $^{1}$ \\ ${ }^{1}$ Department of Polymeric Chemical Engineering, Polytechnic of STMI Jakarta, 10510, Jakarta, \\ Indonesia \\ ${ }^{2}$ Department of Automotive Industrial Engineering, Polytechnic of STMI Jakarta, 10510, Jakarta, \\ Indonesia
}

\begin{abstract}
Grey Relational Analyses (GRA) was utilized to determine optimal setting parameters of Free Fatty Acid (FFA) conversion from into hydrocarbon chain by decarboxylation process. The considered setting parameters were voltage and acetic acid $\left(\mathrm{CH}_{3} \mathrm{COOH}\right)$ concentration. Decarboxylation process occurred by adding acetic acid as the ion contributor for the dimerization process. In order to facilitate FFA well ionized, electrolysis was employed during the decarboxylation with voltage varied from 10 Volt to 25 Volt. The concentration of Acetic Acid varied from $0.5 \mathrm{M}$ to $1.5 \mathrm{M}$ for an optimum condition with a high yield. Decarboxylation reaction took place at $130^{\circ} \mathrm{C}$ for 1 hour. The experiments were carried out by using full factorial design and multi responses considering \% Yield, specific gravity (spgr), ${ }^{\circ} \mathrm{API}$, viscosity, and Net Heating Value (NHV). Grey Reasoning Grade (GRG) was used to analysis multi responses. The setting parameters of sequence seven (A2 B3) has the highest GRG. Analysis of variance (ANOVA) results indicated that acetic acid concentration was contributing parameter. The optimal level for acetic acid concentration based on polynomial regression model was found to be $1.325 \mathrm{M}$.
\end{abstract}

\section{Introduction}

Biodiesel is commonly known as short-chain mono-alkyl esters of long-chain fatty acids derived from renewable lipid feedstocks, such as vegetable oil or animal fats [1]. If all of the produced edible oils are transesterified, the petrol-diesel global consumption can be replaced until $3 \%$.

Biodiesel has more advantages than petrol-diesel due to its shorter carbon chain, this results biodiesel is more flammable. It has no sulfur content which sulfur may damage the environment as a pollutant. Biodiesel is more available as a renewable energy than fossil fuel. Furthermore, it can be directly employed in existing engines, vehicles and

*Corresponding author: erfina@kemenperin.go.id 
infrastructure [2]. It also has a better energy balance than petrol-diesel because it contains 3.2 times the amount of energy it takes to produce it [3].

There are some properties that classified a good biodiesel i.e: contains Carbon (wt) $80 \%$, Hydrogen (wt) $13 \%, 0.8$ specific gravity, Cetane number at $40-45$, viscosity at 3 $\mathrm{mm}^{2} / \mathrm{s}$ [4]. However, biodiesel which consists of fatty acid alkyl esters has some drawbacks. Biodiesel has a low fluidity, high oxygen content, poor stability of thermal oxidation and polymerization of ester fuel molecule [3]. Decarboxylation of Free Fatty Acid (FFA) is regarded as one of solutions to solve these problems, that can directly convert FFA into hydrocarbon chains.

There are several factors that influence Free Fatty Acid (FFA) decarboxylation process into hydrocarbon chain [5]. The selection of the right setting parameter for each factor is needed to have an optimal quality characteristics. A full-factors design of experiments (DOE) can be proposed as a method to select the right setting parameter. DOE methods can evaluate each factor's effect on average and variability in quality characteristics[6]. Although DOE has the advantage, this method has limitations in handling multi responses of quality characteristics.

Free Fatty Acid (FFA) decarboxylation process into hydrocarbon chain has some responses as quality characteristics considering \% Yield, Net Heating Value (NHV), specific gravity (spgr), ${ }^{\circ}$ API and viscosity. Therefore, it needs a method to solve multi responses problem. There are several methods for solving multi responses problem such as engineering judgement, regression analysis, Principal Component Analysis (PCA) and Grey Relational Analysis (GRA) [7]. The knowledge and experience of engineers are commonly used for engineering judgement which results its weakness. This method is only suitable for experienced engineers. Regression analysis is basically a technique-based approach to regression for each quality characteristic. Using regression analysis for solving multi response can increase complexity in the calculation and possibility of a correlation between quality characteristics not adequately considered. PCA transforms multi response into key components that are not correlated. PCA methodbhas difficulties in determining a feasible solution if there are more than one component that has eigen value more than one or there are more than one main component selected. GRA converts multi responses to the value of Grey Relational Grade (GRG) and optimizes the parameters by analyzing the GRG. GRA is based on the theory of Grey System can provide weighting factors that influence processes and can be applied to solve problems of complex multi responses of quality characteristics [8]. DOE based on the Grey Relational Analysis (GRA) offers an approach transforming single response optimization to multi response optimization processes.

\section{Literature review}

Catalytic decarboxylation of benzoic acid was performed by Takemura et.al. (1985) at the temperature range of $370-440^{\circ} \mathrm{C}$ in a batch autoclave with $\mathrm{Y}$ type zeolite. From the three rare earth metal-exchanged Y zeolite catalysts, NdHY resulted the highest activity, on which the benzene yield was $75.6 \%$ under nitrogen at $390^{\circ} \mathrm{C}$ [9]. Watanabe et.al. (2005) proposed a reaction mechanism based on the decarboxylation experiment of stearic acid $(\mathrm{C} 17 \mathrm{H} 35 \mathrm{COOH})$ using batch reactor with supercritical water $(\mathrm{SCW})$ of $400^{\circ} \mathrm{C}$ and 0.17 $\mathrm{g} / \mathrm{cm}^{3}$ for $30 \mathrm{~min}$. Furthermore, it was found that the addition of alkali hydroxide $(\mathrm{NaOH}$ and $\mathrm{KOH}$ ) in the SCW reaction could enhance the decarboxylation of $\mathrm{C} 17$-acid with the main products being $\mathrm{CO}_{2}$ and $\mathrm{C}_{17}$ alkane [10]. Kolbe electrolysis of potassium salts of coconut fatty acids and acetic acid using platinum electrodes has produced a clear liquid product ( $58 \%$ theoretical yield) with very good diesel-fuel properties through the studies of 
Sumera et.al. (1990). The analysis of the liquid product showed that it contained $83 \%$ straight chain hydrocarbons[5].

Grey Relational Grade was used by Deng (1989) in Grey System to measure the level of approximation among sequences[11]. Recently, the optimization of process parameters for multi responses using GRA have been investigated. Taguchi method is commonly used instead of full factorial DOE in performing experiment. Kalsi et. al, (2013) used Taguchi based GRA for optimizing in turning process [12]. There are some researches that comparing GRA and other method for optimizing multi responses. Johny et. al, (2016) compared Taguchi based GRA and Taguchi based PCA as an optimization method [13]. Jeyapaul et al. (2005) compared engineering judgement, regression analysis, Principal Component Analysis (PCA), and Grey Relational Analysis (GRA) methods on optimizing multi responses experiment [7].

\section{Methods}

\subsection{Experiment}

Crude Palm Oil (CPO) was first hydrolysed at $120^{\circ} \mathrm{C}$ using Sulfuric Acid as the catalyst with excess water for 2 hours. The volume ratio between water and CPO was 16:1. Products obtained in two layers after settling for 3 hours which upper layer was FFA and the lower layer was glycerol with water. FFA then separated to be employed as feed in the decarboxylation. $12 \mathrm{~L}$ of FFA was flowed into a reactor with $600 \mathrm{ml} \mathrm{CH} 3 \mathrm{COOH}$ as the catalyst in the concentration range $0,5-1,5 \mathrm{M}$. Electrolysis was occured in the voltage range $10-25$ volt at $130^{\circ} \mathrm{C}$. Two electrodes were employed i.e. silver $(\mathrm{Ag})$ and copper $(\mathrm{Cu})$. This decarboxylation with the aid of electrolysis took 2 hours to produce hydrocarbon chain.

\subsection{Optimization}

There are factors that influenced Free Fatty Acid (FFA) decarboxylation process into hydrocarbon chain such as temperature, pressure, voltage and electrolyte concentration [5]. Two control factors were determined based on screening experiments, namely voltage and electrolyte concentration (acetic acid). Each parameter was designed to have different level, three levels of acetic acid concentration and four levels for voltage which are shown in Table 1.

Table 1. Experiment level factor

\begin{tabular}{|l|l|l|l|l|l|c|}
\hline \multicolumn{3}{|c|}{ Factor } & \multicolumn{4}{c|}{ Level } \\
\hline \multirow{3}{*}{$\begin{array}{l}\text { Control } \\
\text { factor }\end{array}$} & Coded & \multicolumn{1}{|c|}{ Uncoded } & 1 & 2 & 3 & 4 \\
\cline { 2 - 8 } & A & Acetic acid concentration & $0,5 \mathrm{M}$ & $1 \mathrm{M}$ & $1,5 \mathrm{M}$ & \\
\cline { 2 - 8 } & B & Voltage & $10 \mathrm{~V}$ & $15 \mathrm{~V}$ & $20 \mathrm{~V}$ & $25 \mathrm{~V}$ \\
\hline
\end{tabular}

According to factorial design, an experimental design with two factors with three and four levels required twelve experiments. In this process, each experiment was conducted with three repetitions (M1, M2, M3). Replication was used to measure of variance that arises. Sequence number of experiments was employed from the Minitab as shown in Table 2. \% Yield, NHV, spgr, \%API, and viscosity, were measured as quality characteristics from each experiment. Response variables data from each experiment are summarized in Table 3. 
Table 2. Sequence numbers of experiments

\begin{tabular}{|c|c|c|c|c|c|}
\hline \multirow{2}{*}{$\begin{array}{c}\text { Sequence } \\
\text { Number }\end{array}$} & \multicolumn{2}{|c|}{ Control factor } & \multicolumn{3}{c|}{ Repetitions } \\
\cline { 2 - 6 } & $\mathrm{A}$ & $\mathrm{B}$ & $\mathrm{M} 1$ & $\mathrm{M} 2$ & $\mathrm{M} 3$ \\
\hline 1 & 1 & 1 & 8 & 13 & 24 \\
\hline 2 & 1 & 2 & 10 & 15 & 16 \\
\hline 3 & 1 & 3 & 22 & 25 & 26 \\
\hline 4 & 1 & 4 & 6 & 31 & 32 \\
\hline 5 & 2 & 1 & 2 & 12 & 33 \\
\hline 6 & 2 & 2 & 5 & 9 & 28 \\
\hline 7 & 2 & 3 & 17 & 20 & 35 \\
\hline 8 & 2 & 4 & 4 & 7 & 29 \\
\hline 9 & 3 & 1 & 3 & 14 & 27 \\
\hline 10 & 3 & 2 & 11 & 19 & 23 \\
\hline 11 & 3 & 3 & 1 & 18 & 30 \\
\hline 12 & 3 & 4 & 21 & 34 & 36 \\
\hline
\end{tabular}

Table 3. Experiment's result

\begin{tabular}{|c|c|c|c|c|c|c|c|c|c|c|c|c|c|c|c|}
\hline \multirow{2}{*}{ Seq } & \multicolumn{3}{|c|}{$\%$ Yield } & \multicolumn{3}{|c|}{ spgr } & \multicolumn{3}{|c|}{${ }^{\circ} \mathrm{API}$} & \multicolumn{3}{|c|}{ Viscosity } & \multicolumn{3}{|c|}{ NHV } \\
\hline & M1 & M2 & M3 & 41 & M2 & M3 & M1 & M2 & M3 & 41 & M2 & 3 & M1 & 12 & M3 \\
\hline 1 & 47 & 48 & 48 & 0.95 & 0.97 & 0.96 & 16 & 16.5 & 16.3 & 0.26 & 0.25 & 0.26 & 17774.4 & 17780.1 & 17770.0 \\
\hline 2 & 49.8 & 50 & 51 & 0.97 & 0.965 & 0.97 & 18.3 & 18.6 & 18.9 & 0.21 & 0.2 & 0.23 & 17750.0 & 17751.3 & 17751.3 \\
\hline 3 & 57.2 & 58 & 58 & 0.96 & 0.96 & 0.96 & 23 & 23.5 & 23.2 & 0.17 & 0.18 & 0.17 & 7776.8 & 17776.5 & 17776.3 \\
\hline 4 & 56.8 & 57 & 30 & 0.87 & 0.86 & 0.86 & 22 & 22.6 & 23 & 0.23 & 0.26 & & .0 & 1828 & 8282.0 \\
\hline 5 & 67.9 & 68 & 69 & 0.97 & 0.97 & 0.96 & 23.5 & 23.3 & 23.6 & 0.92 & 0.93 & 93 & .5 & 17740.0 & 17740.1 \\
\hline 6 & 66.5 & 66 & 67 & 0.86 & 0.86 & 0.87 & 33 & 32.4 & 32.6 & 1.14 & 1.17 & 1.18 & 8303.6 & 18304.0 & 18303.0 \\
\hline 7 & 67.9 & 68 & 68 & 0.86 & 0.87 & 0.87 & 32.8 & 33.1 & 33.2 & 1.28 & 1.25 & 1.27 & 5.2 & 18304.9 & 18305.0 \\
\hline 8 & 73 & 74 & 14 & 0.86 & 0.85 & 1 & 32.7 & 32.8 & 32.6 & 1.22 & 1.25 & & & 18317.1 & 8317.0 \\
\hline 9 & 81 & 80 & 83 & 0.92 & 0.9 & 0.93 & 19 & 19.3 & 18.9 & 1.75 & 1.73 & 1.76 & 8041.5 & 18045.0 & 18041.0 \\
\hline 10 & 82.7 & 83 & 83 & 0.88 & 0.87 & 0 & 28 & 28.3 & 28.4 & 1.8 & 1.76 & 1.81 & .3 & 18205.2 & 18206.0 \\
\hline 11 & 85 & 86 & 85 & 0.885 & 0.87 & 0.89 & 28.3 & 28.4 & 28.3 & 1.09 & 1.08 & 1.08 & & 18204.1 & 18204.5 \\
\hline 12 & 84.5 & 85 & 85 & 0.86 & 0.86 & 0.88 & 26 & 27 & 26.6 & 1.01 & 1.02 & 1 & 18298.0 & 18297.8 & 18297.6 \\
\hline
\end{tabular}

The GRA is principally measure relational analysis. This approach is suitable for process with incomplete information or uncertain model. The result of the relational analysis is a set of discreet number. Normalization of experimental data, range within 0 to 1 , was conducted and called grey relational generating. Quality characteristic can be divided into three criteria, 'larger the better', 'smaller the better', and 'nominal the best'. Criteria of quality characteristics for Free Fatty Acid (FFA) decarboxylation process into hydrocarbon chain are 'larger thebetter' for \% Yield, 'API, NHV, and 'nominal the best' for spgr, viscosity. 'larger-the-better' responses were normalized using equation (1) and 'nominal the best' were normalized using equation (2)

$$
\begin{gathered}
x_{i}^{*}(k)=\frac{x_{i}^{o}(k)-\min x_{i}^{o}(k)}{\max x_{i}^{o}(k)-\min x_{i}^{o}} \\
x_{i}^{*}(k)=1-\frac{\left|x_{i}^{o}(k)-x_{0}^{o}(k)\right|}{\max \left(\max x_{i}^{o}(k)-x_{0}^{o}(k), x_{0}^{o}(k)-\min x_{i}^{o}(k)\right)}
\end{gathered}
$$


where $x_{i}^{*}(k)$ is the normalized value, $x_{i}^{o}(k)$ is mean value of each response, $x_{0}^{o}(k)$ is target value, and $\max x_{i}^{o}(k)$ is the largest mean response, $\min x_{i}^{o}(k)$ is the smallest mean response, $i=1,2,3, \ldots, 12$. All sequences after application the data preprocessing through Eq. (1) and (2) are shown in Table 4.

Table 4. Normalized value

\begin{tabular}{|c|c|c|c|c|c|}
\hline Running & \% Yield & Spgr & ${ }^{\circ}$ API & Viscosity & NHV \\
\hline 1 & 0.0000 & 0.0847 & 0.0000 & 0.0570 & 0.0600 \\
\hline 2 & 0.0658 & 0.0000 & 0.1392 & 0.0274 & 0.0185 \\
\hline 3 & 0.2633 & 0.0847 & 0.4155 & 0.0000 & 0.0630 \\
\hline 4 & 0.2536 & 0.9322 & 0.3738 & 0.0547 & 0.9394 \\
\hline 5 & 0.5463 & 0.0169 & 0.4294 & 0.5154 & 0.0000 \\
\hline 6 & 0.5009 & 0.9322 & 0.9781 & 0.6773 & 0.9765 \\
\hline 7 & 0.5365 & 0.9661 & 1.0000 & 0.7480 & 0.9791 \\
\hline 8 & 0.6895 & 0.8983 & 0.9801 & 0.7343 & 1.0000 \\
\hline 9 & 0.8977 & 0.5254 & 0.1670 & 0.9236 & 0.5240 \\
\hline 10 & 0.9422 & 0.9322 & 0.7137 & 0.8940 & 0.8066 \\
\hline 11 & 1.0000 & 0.8814 & 0.7197 & 0.6226 & 0.8045 \\
\hline 12 & 0.9884 & 0.9661 & 0.6123 & 0.5724 & 0.9666 \\
\hline
\end{tabular}

The larger normalized results should be expected, therefore; best normalized result should be equal to one. The relation between the best (ideal) and each normalized value can be shown by grey relational coefficient (GRC). GRC wascalculated using the following equation:

$$
\xi_{\mathrm{i}}(\mathrm{k})=\frac{\Delta \min +\xi \Delta \max }{\Delta_{0 \mathrm{i}}(\mathrm{k})+\xi \Delta \max }
$$

where, $\Delta_{0 \mathrm{i}}(\mathrm{k})$ is an absolute value of the difference between $x_{0}^{*}(\mathrm{k})$ andx ${ }_{i}^{*}(\mathrm{k}), \Delta_{0 \mathrm{i}}(\mathrm{k})=$ $\left|\mathrm{x}_{0}^{*}(\mathrm{k})-\mathrm{x}_{i}^{*}(\mathrm{k})\right|, \Delta \mathrm{min}$ is the minimum value of the absolute differences of all comparing sequences. $\Delta \max$ is the maximum value of the absolute differences of all comparing sequences. $\xi$ is the identification coefficient and its value is between 0 and 1 . This research used 0.5 for coefficient. Grey relational grade (GRG) was calculated to express level of correlation and an average of the GRC. It was calculated using the following equation:

$$
\overline{y_{J}}=\frac{1}{k} \sum_{i=1}^{m} \xi_{\mathrm{i}}(\mathrm{k})
$$

All sequences after application the data preprocessing for coefficients and grades using Equation (3) and (4) are listed in Table 5.

\section{Result and discussion}

Table 5 demonstrates that the parameters setting of sequence seven (A2 B3) has the highest GRG. In addition, the average of the GRG for each level of the parameters setting is summarized and given in Table 6. Furthermore, the total average of the GRG for the twelve sequences experiment was calculated to be 0.6359 as shown in Table 6 . 
Table 5. GRC and GRG

\begin{tabular}{|c|c|c|c|c|c|c|}
\hline \multirow{2}{*}{ Sequence } & \multicolumn{5}{|c|}{ GRC } & \multirow{2}{*}{ GRG } \\
\cline { 2 - 6 } & \% Yield & spgr & ${ }^{\circ}$ API & Viscosity & NHV & \\
\hline 1 & 0.3333 & 0.3540 & 0.3333 & 0.3476 & 0.3472 & 0.3431 \\
\hline 2 & 0.3486 & 0.3333 & 0.3674 & 0.3401 & 0.3375 & 0.3454 \\
\hline 3 & 0.4043 & 0.3540 & 0.4610 & 0.3333 & 0.3479 & 0.3801 \\
\hline 4 & 0.4011 & 0.9344 & 0.4440 & 0.3470 & 0.8919 & 0.6037 \\
\hline 5 & 0.5243 & 0.3373 & 0.4670 & 0.5308 & 0.3333 & 0.4385 \\
\hline 6 & 0.5004 & 0.9344 & 0.9581 & 0.6522 & 0.9552 & 0.8001 \\
\hline 7 & 0.5189 & 1.0000 & 1.0000 & 0.7245 & 0.9600 & $\mathbf{0 . 8 4 0 7}$ \\
\hline 8 & 0.6169 & 0.8769 & 0.9618 & 0.7093 & 1.0000 & 0.8330 \\
\hline 9 & 0.8301 & 0.5229 & 0.3751 & 1.0000 & 0.5123 & 0.6481 \\
\hline 10 & 0.8963 & 0.9344 & 0.6359 & 0.9397 & 0.7211 & 0.8255 \\
\hline 11 & 1.0000 & 0.8507 & 0.6408 & 0.6054 & 0.7189 & 0.7632 \\
\hline 12 & 0.9774 & 1.0000 & 0.5633 & 0.5680 & 0.9374 & 0.8092 \\
\hline
\end{tabular}

Table 6. Response table for GRG.

\begin{tabular}{|c|c|c|c|c|c|c|c|}
\hline \multicolumn{2}{|r|}{ Factor } & \multicolumn{4}{|c|}{ Level } & \multirow{2}{*}{ Delta } & \multirow{2}{*}{ Rank } \\
\hline Coded & Uncoded & 1 & 2 & 3 & 4 & & \\
\hline A & $\begin{array}{l}\text { Acetic acid } \\
\text { concentration }\end{array}$ & 0.4181 & 0.7281 & 0.7615 & & 0.3434 & 1 \\
\hline B & Voltage & 0.4766 & 0.6570 & 0.6613 & 0.7486 & 0.2720 & 2 \\
\hline
\end{tabular}

DOE based GRA can provide optimal parameters for multi responses of quality characteristics. Additionally, analysis of variance (ANOVA) on the grey relational grade was conducted to determine the effect of process parameters andidentifythe significant factors. ANOVA analysis was performed with a $95 \%$ confidence level and $5 \%$ significance level. As listed in Table 7, ANOVA analysis was carried out to see the effects of the experimental parameters on the result. The results of the ANOVA in Table 7 indicates that voltage has no statistically significance on the GRG values.

Table 7. Anova for GRG

\begin{tabular}{|c|c|c|c|c|c|c|}
\hline $\begin{array}{c}\text { Control } \\
\text { Factors }\end{array}$ & $\begin{array}{c}\text { Degree of } \\
\text { freedom }\end{array}$ & Sum Square & Adj SS & Adj MSE & $\mathrm{F}$ & $\mathrm{P}_{\text {value }}$ \\
\hline A & 2 & 0,28684 & 0,28684 & 0,14342 & 14,06 & 0,005 \\
\hline B & 3 & 0,11754 & 0,11754 & 0,03918 & 3.84 & 0,076 \\
\hline Error & 6 & 0,06119 & 0,06119 & 0,01020 & & \\
\hline Total & 11 & 0,46557 & & & & \\
\hline
\end{tabular}

Considering that voltage has no statistically significance on the GRG, regression model is built in software Minitab. Voltage will give a significance effect if its level difference more than 15 Volt [10]. Regression is conducted to analyze between output parameter (GRG) and one input parameter (acetic acid concentration). As shown by Fig 1, regression model fits into the following equation:

$$
G R G=-0,1685+0.7248 A-0.1383 A^{2}
$$

The optimal level for acetic acid concentration (A) based on polynomial regression model is found to be at level 2.62 or $1.325 \mathrm{M}$. 


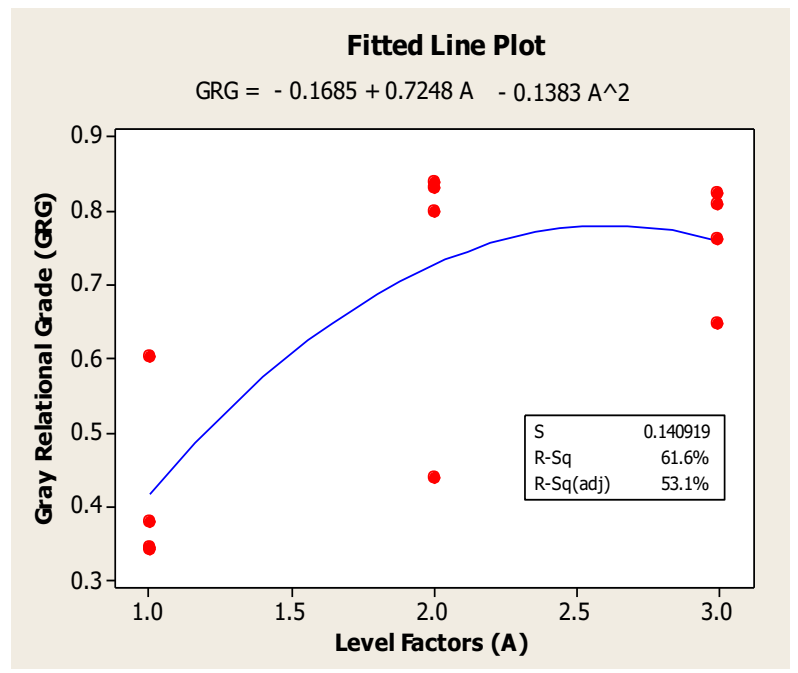

Fig. 1. Regression level factors on GRG

\section{Conclusions}

This paper focuses on application of DOE based GRA to optimize the parameters Free Fatty Acid (FFA) decarboxylation process into hydrocarbon chain such as acetic acid concentration and voltage. Decarboxylation process has multiple quality characteristics, $\%$ Yield, NHV, spgr, \%API, and viscosity. The application of DOE based GRA directly combined the multiple responses into a single performance characteristic called grey relational grade (GRG). The multi responses optimization results demonstrated that the parameters setting of sequence seven (A2 B3) has the highest GRG, combination of $1 \mathrm{M}$ values acetic acid concentration and $20 \mathrm{~V}$ voltage. They were the recommended levels of the controllable parameters concurrently considered. Analysis of variance (ANOVA) was utilized to determine the effect of factors on GRG. ANOVA results demonstrated that voltage had no statistically significance on the GRG values. Polynomial regression model was developed to know the optimal parameter for acetic acid concentration which had statistically significance on the GRG values. It was found out to be $1.325 \mathrm{M}$.

This work was partially supported by Polytechnic STMI Jakarta, Ministry of Industry, Republic of Indonesia.

\section{References}

1. L.P. Christopher, A. Kumar, V.P. Zambare, Appl. Energy, 119, 497 (2014)

2. M. Aghbashlo, A. Demirbas, Biofuel Research Journal, 10, 379 (2016)

3. J. Van Gerpen, B. Shanks, R. Pruszko, D. Clements, G. Knothe, Biodiesel Production Technology, Golden, (National Renewable Energy Laboratory, USA, 2004)

4. S. K. Hoekman, B. Amber, R. Curtis, C. Eric, N. Mani, Renew. Sustainable Energy Rev., 16, 143 (2012)

5. F.C. Sumera, S. Sadain, Philipp. J. Sci., 119(4), 333 (1990)

6. I. Soejanto, Desain Eksperimen Dengan Metode Taguchi, (Graha Ilmu, Yogyakarta, 2009)

7. R. Jeyapaul, P. Shahabudeen, K. Krishniah, Int. J. Adv. Manuf. Tech., 26, 1331 (2005) 
8. Y.M. Chiang, H.H. Hsien, Computer and Industrial Engineering Journal, 56(2), 648 (2009)

9. Y. Takemura, A. Nakamura, H. Taguchi, Ind. Eng. Chem. Prod. Res. Dev., 24(2), 213 (1985)

10. M. Watanabe, T. Iida, H. Inomata, Energ, Convers, Manage., 47, 3344 (2016)

11. J.L. Deng, J. Grey. Syst., 1, 1 (1989)

12. N.S. Kalsi, R. Sehgal, V.S. Sharma, International Journal of Strategic Decision Sciences, 4(2), 79 (2013)

13. S.M. Johny, C.R. Sri Sai, V.R. Rao, B.G. Singh, Int. Res. J. Eng. Tech., 3, 680 (2016) 